Pacific Journal of Mathematics

SOME GEOMETRIC PROPERTIES RELATED TO THE FIXED
POINT THEORY FOR NONEXPASIVE MAPPINGS 


\title{
SOME GEOMETRIC PROPERTIES RELATED TO THE FIXED POINT THEORY FOR NONEXPANSIVE MAPPINGS
}

\author{
J.-P. Gossez and E. Lami Dozo
}

\begin{abstract}
The main result of this paper asserts that if a Banach space admits a sequentially weakly continuous duality function, then a condition introduced by Opial to characterize weak limits by means of the norm is satisfied and the space has normal structure in the sense of Brodskii-Milman. This result of geometric nature allows some unification in the fixed point theory for both single-valued and multi-valued non-expansive mappings.
\end{abstract}

Let $K$ be a nonempty weakly compact convex subset of a real Banach space $X$ and let $T$ be a nonexpansive mapping of $K$ into its nonempty compact subsets (i.e., $D(T x, T y) \leqq\|x-y\|$ for all $x, y \in K$, where $D($,$) denotes the Hausdorff metric). While the question of the$ existence of a fixed point for $T$ remains open, several positive results were proved recently under various conditions of geometric type on the norm of $X$. We list here the conditions we have in mind:

(I) (Browder [5]) $X$ admits a sequentially continuous duality function $F_{\phi}: X, \sigma\left(X, X^{*}\right) \rightarrow X^{*}, \sigma\left(X^{*}, X\right)$ (i.e., a function $F_{\phi}$ such that $\left\langle x, F_{\phi}(x)\right\rangle=\|x\|\left\|F_{\phi}(x)\right\|$ and $\left\|F_{\phi}(x)\right\|=\phi(\|x\|)$ for all $x \in X$, where $\phi: \boldsymbol{R}^{+} \rightarrow \boldsymbol{R}^{+}$is continuous strictly increasing with $\phi(0)=0$ and $\phi(+\infty)=+\infty)$.

(II) (Opial [17]) If a sequence $\left\{x_{n}\right\}$ converges weakly in $X$ to $x_{0}$, then $\lim \inf \left\|x_{n}-x\right\|>\lim \inf \left\|x_{n}-x_{0}\right\|$ for all $x \neq x_{0}$.

(III) (Brodskii-Milman [4]) Every weakly compact convex subset $H$ of $X$ has normal structure (i.e., for each convex subset $L$ of $H$ which contains more than one point there exists $x \in L$ such that $\sup \{\|x-y\| ; y \in L\}<\sup \{\|u-v\| ; u, v \in L\})$.

When $T$ is single-valued, the existence of a fixed point for $T$ in $K$ was proved by Browder [5] if $X$ satisfies (I) and if $T$ can be extended outside $K$ in a nonexpansive way, and by Kirk [12] if $X$ satisfies (III). A similar situation occurs in the multivalued case where one also encounters two different approaches: one by Browder [6] who proved a fixed point theorem under condition (I) and some additional assumptions, and another by the second author [14] who obtained the same conclusion under condition (II).

It is a consequence of our main theorem that in both cases the 
second approach is more general than the first ${ }^{1}$ :

Theorem 1. (I) implies (II) and (II) implies (III). No converse implication holds, not even when $X$ and $X^{*}$ are supposed to be uniformly convex.

Although (II) does not imply (I), there is some result in that direction, which supports the feeling that the gap between (II) and (III) is much deeper than that between (I) and (II). To state this result we define $\left(\mathrm{I}_{0}\right)$ as $(\mathrm{I})$ except that $F_{\phi}$ is only required to be sequentially continuous at zero and $\left(\mathrm{II}_{0}\right)$ as (II) except that $>$ is replaced by $\geqq$.

THEOREM 2. $\left(\mathrm{I}_{0}\right)$ implies $\left(\mathrm{II}_{0}\right)$. The converse implication holds when the norm of $X$ is uniformly Gâteaux differentiable.

Theorems 1 and 2 are proved in $\S 2$ and $\S 3$ respectively. Some related results and several examples are presented in $\$ 4$ which shed more light on the connections between these geometric properties.

In $\S 5$ we show that the space $c_{0}$ endowed with Day's norm, which is locally uniformly convex (cf. [18]), does not satisfy (III). This example should be connected with the well-known facts that all uniformly convex spaces, as well as the spaces showed by Day and Lovaglia to be locally uniformly convex but not isomorphic to any uniformly convex space, satisfy (III) (cf. $[3,6,11]$ ).

2. The main result. To prove Theorem 1 we need two lemmas about the duality map $J_{\dot{\phi}}: X \rightarrow 2^{X *}$ defined by

$$
J_{\phi}(x)=\left\{x^{*} \in X^{*} ;\left\langle x, x^{*}\right\rangle=\|x\|\left\|x^{*}\right\| \text { and }\left\|x^{*}\right\|=\phi(\|x\|)\right\}
$$

for all $x \in X$. In this context condition (I) asserts the existence for some gauge $\phi$ of a sequentially weakly continuous selection for $J_{\phi}$. The first lemma follows from the monotonicity of $J_{\phi}$; it has been extended in [10] to general monotone operators.

Lemma 1. If $X$ satisfies (I) (for some gauge $\phi$ ), then $J_{\phi}$ is singlevalued (for any gauge $\phi$ ).

Proof. The monotone operator $F_{\phi}$ is hemicontinuous by (I), thus maximal monotone by Minty's classical argument [15]. Since $J_{\phi}$ is

${ }^{1}$ It should be noticed that the existence theorems of [12] and [14] have been recently extended in [13] and [2] where it is only required that $T$ maps the boundary of $K$ into $K$. 
also monotone we must have $J_{\phi}=F_{\phi}$. That $J_{\psi}$ is single-valued for another gauge $\psi$ follows from the equality $J_{\psi}(x)=\psi(\|x\|) / \phi(\|x\|) J_{\phi}(x)$.

The second lemma uses the observation of Asplund [1] that $J_{\phi}$ is the subdifferential of the convex function $\Phi(\|x\|)$ where

i.e.,

$$
\Phi(t)=\int_{0}^{t} \phi(s) d s
$$

$$
J_{\phi}(x)=\left\{x^{*} \in X^{*} ; \Phi(\|y\|) \geqq \Phi(\|x\|)+<y-x, x^{*}>\forall y \in X\right\} .
$$

Lemma 2. If $J_{\phi}$ is single-valued then

$$
\Phi(\|x+y\|)=\Phi(\|x\|)+\int_{0}^{1}<y, J_{\phi}(x+t y)>d t
$$

for all $x, y \in X$.

Proof. If $J_{\phi}$ is single-valued then $J_{\phi}$ is the Gâteaux gradient of $\Phi(\|x\|)$; this follows from a general result in the theory of convex functions (see [16; p. 66]). But $J_{\phi}$ is easily verified to be hemicontinuous. Consequently the lemma just expresses the fact that a function of a real variable is the integral of its continuous derivative.

Proof of Theorem 1. Assume (I) and let $x_{n} \rightarrow x_{0}(\rightarrow$ will denote weak convergence, $\rightarrow$ norm convergence). By Lemmas 1 and 2,

$$
\begin{aligned}
\Phi\left(\left\|x_{n}-x\right\|\right)= & \Phi\left(\left\|x_{n}-x_{0}\right\|\right) \\
& +\int_{0}^{1}<x_{0}-x, J_{\phi}\left(\left(x_{n}-x_{0}\right)+t\left(x_{0}-x\right)\right)>d t
\end{aligned}
$$

for all $x \in X$, so

$$
\lim \inf \Phi\left(\left\|x_{n}-x\right\|\right) \geqq \lim \inf \Phi\left(\left\|x_{n}-x_{0}\right\|\right)+\lim \inf \int_{0}^{1} \cdots d t .
$$

The sequential weak continuity of $J_{\phi}$ and the dominated convergence theorem give

$$
\begin{aligned}
& \lim \inf \Phi\left(\left\|x_{n}-x\right\|\right) \geqq \lim \inf \Phi\left(\left\|x_{n}-x_{0}\right\|\right) \\
& \quad+\int_{0}^{1}\left\|x_{0}-x\right\| \Phi\left(\frac{t}{t}\left\|x_{0}-x\right\|\right) d t
\end{aligned}
$$

an inequality which clearly implies condition (II).

The proof that (II) implies (III) relies upon a characterization of normal structure given in [11]: $X$ satisfies (III) if and only if $X$ does not contain a diametral sequence $\left\{x_{n}\right\}$ weakly converging to zero (i.e., a nonconstant sequence with

$$
d\left(x_{n} ; \operatorname{co}\left\{x_{1}, \cdots, x_{n-1}\right\}\right) \rightarrow \delta\left(\left\{x_{n}\right\}\right),
$$


where $d\left(x_{n} ;\right.$ co $\left.\left\{x_{1}, \cdots, x_{n-1}\right\}\right)$ denotes the distance of $x_{n}$ to the convex hull of $\left\{x_{1}, \cdots, x_{n-1}\right\}$ and $\delta\left(\left\{x_{n}\right\}\right)$ the diameter of $\left.\left\{x_{n}\right\}\right)$.

Assume that (III) does not hold and take such a sequence. It follows from (2) that

$$
\lim \left\|x_{n}-y\right\|=\delta\left(\left\{x_{n}\right\}\right)
$$

for all $y \in \operatorname{co}\left\{x_{n}\right\}$, hence for all $y \in \overline{c o}\left\{x_{n}\right\}$. Taking $y=0$, we get $\lim \left\|x_{n}\right\|=\delta\left(\left\{x_{n}\right\}\right)$, but for each $y=x_{n_{0}}$ we obtain $\lim \left\|x_{n}-x_{n_{0}}\right\|=$ $\delta\left(\left\{x_{n}\right\}\right)$. This contradicts (II).

We now turn to the last part of Theorem 1 . When $1<p<\infty$ $p \neq 2, L^{p}(0,2 \Pi)$ satisfies (III) since it is uniformly convex, but Opial [17] showed that even $\left(\mathrm{II}_{0}\right)$ does not hold. When $1<p \neq q<\infty$ the Hilbert product of $l^{p}$ and $l^{q}$ satisfies (II) (cf. [14]; since it is easily verified that $\left(\mathrm{I}_{0}\right)$ holds, (II) also follows from Theorem 2 of $\S 3$ and Proposition 1 of $\S 4$ ), but Bruck [7] showed that (I) does not hold.

REMARKs 1. A finite dimensional space whose norm is not differentiable provides another example of a space satisfying $\left(\mathrm{I}_{0}\right)$, (II) but not (I) by Lemma 1 .

2. In the Hilbert space case when $\phi(t)=t$, estimation (1) reduces to an estimation obtained by Opial $[17 ; \mathrm{p} .592]$.

3. A partial converse. The following simple lemma whose proof proceeds by taking subsequences will be needed.

LEMMA 3. Conditions (II) and ( $\left.\mathrm{II}_{0}\right)$ are respectively equivalent to the analogous conditions obtained by replacing lim inf by lim sup.

Proof of Theorem 2. Assume $\left(\mathrm{I}_{0}\right)$ and let $x_{n} \rightarrow x_{0}$. As $J_{\phi}$ is the subdifferential of $\Phi(\|x\|)$ we have

$$
\Phi\left(\left\|x_{n}-x\right\|\right) \geqq \Phi\left(\left\|x_{n}-x_{0}\right\|\right)+<x_{0}-x, F_{\phi}\left(x_{n}-x_{0}\right)>
$$

for all $x \in X$, so

$$
\lim \inf \Phi\left(\left\|x_{n}-x\right\|\right) \geqq \lim \inf \Phi\left(\left\|x_{n}-x_{0}\right\|\right),
$$

an inequality which clearly implies condition $\left(\mathrm{II}_{0}\right)$.

In the second part of Theorem 2, the assumption of uniform Gâteaux differentiability is equivalent to the condition that $J_{\phi}$ be singlevalued and continuous on $X,\|\|$ into $X^{*}, \sigma\left(X^{*}, X\right)$, uniformly on bounded sets; this follows easily from a result of Cudia [8; p. 302]. Under this assumption we will show that if $\left(\mathrm{II}_{0}\right)$ holds then for any $\phi, J_{\phi}$ is sequentially weakly continuous at zero.

Let $x_{n} \rightarrow 0$ and suppose that $J_{\dot{\phi}}\left(x_{n}\right)$ does not converge to zero for 
$\sigma\left(X^{*}, X\right)$. Then there exist $z \in X$, a subsequence $\left\{x_{m}\right\}$ and $x^{*} \in X^{*}$ such that $\left\langle z, J_{\phi}\left(x_{m}\right)\right\rangle \rightarrow\left\langle z, x^{*}\right\rangle \neq 0$. Define

$$
f(x)=\lim \sup \Phi\left(\left\|x_{m}-x\right\|\right) ;
$$

$f$ is a continuous convex function on $X$ which assumes its minimum at $x=0$ by condition $\left(\mathrm{II}_{0}\right)$ and Lemma 3 . Hence

$$
\frac{1}{\lambda}(f(-\lambda y)-f(0) \geqq 0 \quad \forall y \in x, \forall \lambda>0,
$$

and thus

$$
\lim \sup \frac{1}{\lambda}\left(\Phi\left(\left\|x_{m}+\lambda y\right\|\right)-\Phi\left(\left\|x_{m}\right\|\right)\right) \geqq 0 ;
$$

as $J_{\phi}$ is the subdifferential of $\Phi(\|x\|)$,

$$
\lim \sup <y, J_{\dot{\phi}}\left(x_{m}+\lambda y\right)>\geqq 0 \text {. }
$$

Letting $\lambda \downarrow 0$, limits can be interchanged by the uniform continuity of $J_{\phi}$, and consequently

$$
\lim \sup <y, J_{\dot{\phi}}\left(x_{m}\right)>\geqq 0 \quad \forall y \in X .
$$

In particular $\left\langle z, x^{*}\right\rangle=0$, a contradiction.

REMARK. We do not know whether the differentiability hypothesis in Theorem 2 is essential.

4. Further connections. We begin this section by showing that the following situation holds in general:

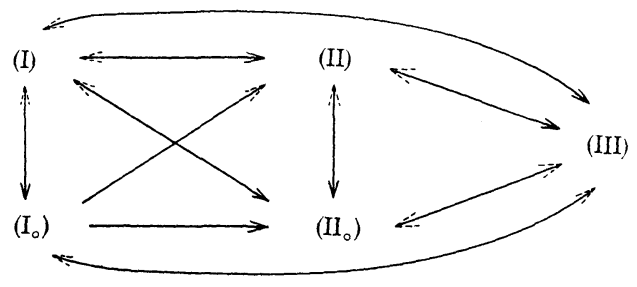

where $(A) \rightarrow(B)[(A) \rightarrow(B)]$ means that $(A)$ implies [does not imply] $(B)$. Taking into account $\S 2$ and 3 , it suffices to exhibit a space satisfying $\left(\mathrm{I}_{0}\right)$ but not (III). Consider the space $l^{2}$ endowed with the norm

$$
\|x\|=\max \left\{\frac{1}{2}\|x\|_{2^{2}} ;\|x\|_{l^{\infty}}\right\}
$$


James [3] proved that (III) does not hold; however the application

$$
x=(x(1), x(2), \cdots) \longrightarrow\left\{\begin{array}{c}
\frac{x}{4} \text { if } \frac{1}{2}\|x\|_{l^{2}} \geqq\|x\|_{l^{\infty}}, \\
\left(0, \cdots, 0, x\left(m_{0}\right), 0, \cdots\right) \text { if } \\
\frac{1}{2}\|x\|_{l^{2}}<\|x\|_{l^{\infty}},
\end{array}\right.
$$

where $m_{0}=\inf \left\{m ; x(m)=\|x\|_{l^{\infty}}\right\}$ and $x\left(m_{0}\right)$ stands at the $m_{0}$-th place, defines a duality function which is sequentially weakly continuous at zero. Another example of a space satisfying ( $\left.\mathrm{I}_{0}\right)$ but not (III) will be given in $\S 5$.

Although $\left(\mathrm{II}_{0}\right)$ does not generally imply (II), one can prove the following proposition which includes Opial's result of [17; lemma 3].

Proposition 1. (II $)$ implies (II) when $X$ is uniformly convex.

This proposition as well as Opial's result are no longer true if the assumption of uniform convexity is weakened to that of local uniform convexity (see the example in $\$ 5$ ).

Proof of Proposition 1. Let $x_{n} \rightarrow x_{0}$ and suppose that

$$
\lim \inf \left\|x_{n}-x\right\|=\lim \inf \left\|x_{n}-x_{0}\right\|
$$

with $x \neq x_{0}$. Then

$$
\lim \inf \left\|x_{n}-\frac{x+x_{0}}{2}\right\|<\liminf \left\|x_{n}-x_{0}\right\|
$$

by uniform convexity, which contradicts $\left(\mathrm{II}_{0}\right)$.

We conclude this section with two results connecting (I) with two classical rotundity conditions.

Proposition 2. If (I) holds then $X$ has property (A), i.e., $x_{n} \rightarrow x$ whenever $x_{n} \rightarrow x$ and $\left\|x_{n}\right\| \rightarrow\|x\|$.

Proof. By Lemmas 1 and 2,

$$
\Phi\left(\left\|x_{n}-x\right\|\right)=\Phi\left(\left\|x_{n}\right\|\right)+\int_{0}^{1}<-x, J_{\phi}\left(x_{n}-t x\right)>d t,
$$

so

$$
\lim \Phi\left(\left\|x_{n}-x\right\|\right)=\Phi(\|x\|)+\int_{0}^{1}<-x, J_{\phi}(x-t x)>d t
$$


Applying Lemma 2 to the last integral, we get $\lim \Phi\left(\left\|x_{n}-x\right\|\right)=0$.

CoRollary. If (I) holds and if $X$ is strictly convex, then $X$ has property $(H)$, i.e., $X$ has property $(A)$ and is strictly convex.

Proposition 3. If (I) holds and if $X$ is strictly convex and reflexive, then $X$ is locally uniformly convex.

Proof. We have to prove that $x_{n} \rightarrow x$ whenever $\left\|x_{n}\right\| \rightarrow\|x\|$ and $\left\|x+x_{n}\right\| \rightarrow 2\|x\|$. Since the balls in $X$ are weakly sequentially compact, it suffices to see that any weakly convergent subsequence $\left\{x_{m}\right\}$ converges in norm to $x$. Let $x_{m} \rightarrow y$. We will show that $y=x$, and the proof will follow from Proposition 2.

By Lemmas 1 and 2,

$$
\Phi\left(\left\|x_{m}+x\right\|\right)-\Phi\left(\left\|x_{m}\right\|\right)=\int_{0}^{1}<x, J_{\phi}\left(x_{m}+t x\right)>d t ;
$$

going to the limit and applying Lemma 2 to the first member, we get

$$
\int_{0}^{1}<x, J_{\phi}(x+t x)>d t=\int_{0}^{1}<x, J_{\phi}(y+t x)>d t .
$$

The first integral equals $\int_{0}^{1}\|x\| \phi(\|x+t x\|) d t$ and the second is majorized by

$$
\int_{0}^{1}\|x\| \phi(\|y+t x\|) d t \leqq \int_{0}^{1}\|x\| \phi(\|x+t x\|) d t
$$

since $\|y\| \leqq\|x\| ;$ consequently

$$
<x, J_{\phi}(y+t x)>=\|x\| \phi(\|y+t x\|) \quad \forall t \in[0,1] .
$$

But the strict convexity of $X$ means that every nonzero $x^{*} \in X^{*}$ assumes its norm at most one point of the unit sphere of $X$. Thus, eliminating the trivial case $x=0$,

$$
\frac{x}{\|x\|}=\frac{y+t x}{\|y+t x\|}
$$

for all $t \in[0,1]$ with $y+t x \neq 0$, an equality which gives $y=k x$ with $k \geqq 0$. It then follows from (3) that $k=1$, which completes the proof.

5. An example. Consider the space $c_{0}$. The formula

$$
\|x\|=\sup \left[\sum_{i=1}^{\infty} 2^{-2 i} x^{2}\left(\alpha_{i}\right)\right]^{1 / 2}
$$

where the supremum is taken over all permutations $\alpha$ of $N$, defines 
on $c_{0}$ an equivalent norm [9] which is known to be locally uniformly convex [18]. We will show that $c_{0}$ endowed with this norm satisfies (I $\mathrm{I}_{0}$ but not (III).

First recall an equivalent definition of \|\| by means of the decreasing rearrangement map $D$ of $c_{0}$ into $l^{2}$ (cf. [9]). Given $x \in c_{0}$, $N$ can be enumerated in a sequence $\left\{\beta_{i}\right\}$ in such a way that $\left|x\left(\beta_{i}\right)\right| \geqq$ $\left|x\left(\beta_{i+1}\right)\right|$ for all $i$ and that $\beta_{i} \leqq \beta_{j}$ if $\left|x\left(\beta_{i}\right)\right|=x\left(\beta_{j}\right) \mid$ and $i \leqq j$. Define $(D x)\left(\beta_{i}\right)=2^{-i} x\left(\beta_{i}\right)$. Then $\|x\|=\|D x\|_{l^{2}}$.

We assert that $D^{2}: c_{0} \rightarrow l^{l}$ is a duality function with gauge $\phi(r)=r$ which is sequentially continuous at zero for $\sigma\left(c_{0}, l^{1}\right)$ and $\sigma\left(l^{1}, c_{0}\right)$. Indeed $D^{2} x$ is defined by $\left(D^{2} x\right)\left(\beta_{i}\right)=2^{-2 i} x\left(\beta_{i}\right)$, and we have

$$
<x, D^{2} x>=\sum_{i=1}^{\infty} 2^{-2 i} x^{2}\left(\beta_{i}\right)=\|D x\|_{l^{2}}^{2}=\|x\|^{2},
$$

while for all $y \in c_{0}$

$$
\begin{aligned}
<y, D^{2} x & >=\sum_{i=1}^{\infty} 2^{-2 i} y\left(\beta_{i}\right) x\left(\beta_{i}\right) \\
& \leqq\left[\sum_{i=1}^{\infty} 2^{-2 i} y^{2}\left(\beta_{i}\right)\right]^{1 / 2}\left[\sum_{i=1}^{\infty} 2^{-2 i} x^{2}\left(\beta_{i}\right)\right]^{1 / 2} \leqq\|y\|\|x\|
\end{aligned}
$$

by definition of the norm. Thus $D^{2}$ is a duality function. The continuity requirement is clearly satisfied.

To prove that (III) does not hold, we construct a diametral sequence $x_{n} \rightarrow 0$ (see the characterization of normal structure mentioned in the proof of Theorem 1). Take $x_{1}=0$ and, for $n>1$,

$$
x_{n}(i)=\left\{\begin{array}{l}
0 \text { if } i \leqq 2^{-1} n(n-1), \\
1 \text { if } 2^{-1} n(n-1)<i \leqq 2^{-1} n(n-1)+n, \\
0 \text { if } i>2^{-1} n(n-1)+n
\end{array}\right.
$$

It is immediate that $\left\langle x_{n}, x^{*}\right\rangle \rightarrow 0$ for each $x^{*} \in l^{1}$, thus $x_{n} \rightarrow 0$. On the other hand

$$
\delta\left(\left\{x_{n}\right\}\right)^{2}=\sup _{n, m}\left\|x_{n}-x_{m}\right\|^{2}=\sup _{n, m} \sum_{i=1}^{n+m} 2^{-2 i}=\sum_{i=1}^{\infty} 2^{-2 i}
$$

but

$$
d\left(x_{n+1}, \operatorname{co}\left\{x_{1}, \cdots, x_{n}\right\}\right)^{2} \geqq \sum_{i=1}^{n+1} 2^{-2 i} \rightarrow \sum_{i=1}^{\infty} 2^{-2} i,
$$

and consequently the sequence is diametral. 


\section{REFERENCES}

1. E. Asplund, Positivity of duality mappings, Bull. Amer. Math. Soc., 73 (1967), 200-203.

2. N. A. Assad and W. A. Kirk, Fixed point theorems for set-valued mappings of contractive type, to appear.

3. L. P. Belluce, W. A. Kirk and E. F. Steiner, Normal structure in Banach spaces, Pacific J. Math., 26 (1968), 433-440.

4. M. S. Brodskii and D. P. Milman, On the center of a convex set, Dokl. Akad. Nauk. SSSR, 59 (1948), 837-840.

5. F. E. Browder, Fixed point theorems for nonlinear semicontractive mappings in Banach spaces, Arch. Rat. Mech. Anal., 21 (1966), 259-269.

6. - Nonlinear operators and nonlinear equations of evolution in Banach Spaces, Proc. Symp. Pure Math., 18, Part 2, Amer. Math. Soc., to appear.

7. R. E. Bruck, Approximating fixed points and fixed point sets of nonexpansive mappings in Banach spaces, Ph. D. Thesis, University of Chicago, 1969.

8. D. F. Cudia, The geometry of Banach spaces, Smoothness, Trans. Amer. Math. Soc., 110 (1964), 284-314.

9. M. M. Day, Strict convexity and smoothness of normed spaces, Trans. Amer. Math. Soc., 78 (1955), 516-528.

10. J. P. Gossez, A note on multivalued monotone operators, Michigan Math. J., 17 (1970), 347-350.

11. J. P. Gossez and E. Lami Dozo, Structure normale et base de Schauder, Bull. Cl. Sc. Ac. R. Belgique, 55 (1969), 673-681.

12. W. A. Kirk, A fixed point theorem for mappings which do not increase distances, Amer. Math. Monthly, 72 (1965), 1004-1006.

13. - Fixed point theorems for nonlinear nonexpansive and generalized contractive mappings, to appear.

14. E. Lami Dozo, Multivalued nonexpansive mappings and Opial's condition, to appear.

15. G. J. Minty, Monotone (nonlinear) operators in Hilbert space, Duke Math. J., 29 (1962), 341-346.

16. J. J. Moreau, Fonctionnelles convexes, Sém. Eq. Dér. Part., Collège de France, Paris, 1967.

17. Z. Opial, Weak convergence of the sequence of successive approximations for nonexpansive mappings, Bull. Amer. Math. Soc., 73 (1967), 591-597.

18. J. Rainwater, Local uniform convexity of Day's norm on $c_{0}(\Gamma)$, Proc. Amer. Math. Soc., 22 (1969), 335-339.

Received May 12, 1971. The first author was supported by the F.N.R.S. in Belgium. Part of the results herein are contained in the second author's doctoral thesis (University of Brussels, 1970).

UNIVERSity of BRUsSels aNd UNIVERSity of CHICAGo, UNIVERSITY OF BRUSSELS. 



\section{PACIFIC JOURNAL OF MATHEMATICS}

\section{EDITORS}

\section{H. SAMELSON}

Stanford University

Stanford, California 94305

\section{R. HOBBY}

University of Washington Seattle, Washington 98105

\section{J. DugundJI}

Department of Mathematics University of Southern California Los Angeles, California 90007

RICHARD ARENS

University of California Los Angeles, California 90024

\section{ASSOCIATE EDITORS}
E. F. BECKENBACH
B. H. Neumann
F. WoLF
K. YoSHIDA

\section{SUPPORTING INSTITUTIONS}

UNIVERSITY OF BRITISH COLUMBIA CALIFORNIA INSTITUTE OF TECHNOLOGY

UNIVERSITY OF CALIFORNIA

MONTANA STATE UNIVERSITY

UNIVERSITY OF NEVADA

NEW MEXICO STATE UNIVERSITY

OREGON STATE UNIVERSITY

UNIVERSITY OF OREGON

OSAKA UNIVERSITY

\author{
UNIVERSITY OF SOUTHERN CALIFORNIA \\ STANFORD UNIVERSITY \\ UNIVERSITY OF TOKYO \\ UNIVERSITY OF UTAH \\ WASHINGTON STATE UNIVERSITY \\ UNIVERSITY OF WASHINGTON \\ * * * * \\ AMERICAN MATHEMATICAL SOCIETY \\ NAVAL WEAPONS CENTER
}

The Supporting Institutions listed above contribute to the cost of publication of this Journal, but they are not owners or publishers and have no responsibility for its content or policies.

Mathematical papers intended for publication in the Pacific Journal of Mathematics should be in typed form or offset-reproduced, (not dittoed), double spaced with large margins. Underline Greek letters in red, German in green, and script in blue. The first paragraph or two must be capable of being used separately as a synopsis of the entire paper. The editorial "we" must not be used in the synopsis, and items of the bibliography should not be cited there unless absolutely necessary, in which case they must be identified by author and Journal, rather than by item number. Manuscripts, in duplicate if possible, may be sent to any one of the four editors. Please classify according to the scheme of Math. Rev. Index. to Vol. 39. All other communications to the editors should be addressed to the managing editor, Richard Arens, University of California, Los Angeles, California, 90024.

50 reprints are provided free for each article; additional copies may be obtained at cost in multiples of 50 .

The Pacific Journal of Mathematics is published monthly. Effective with Volume 16 the price per volume (3 numbers) is $\$ 8.00$; single issues, $\$ 3.00$. Special price for current issues to individual faculty members of supporting institutions and to individual members of the American Mathematical Society: $\$ 4.00$ per volume; single issues $\$ 1.50$. Back numbers are available.

Subscriptions, orders for back numbers, and changes of address should be sent to Pacific Journal of Mathematics, 103 Highland Boulevard, Berkeley, California, 94708.

PUBLISHED BY PACIFIC JOURNAL OF MATHEMATICS, A NON-PROFIT CORPORATION

Printed at Kokusai Bunken Insatsusha (International Academic Printing Co., Ltd.), 270, 3-chome Totsuka-cho, Shinjuku-ku, Tokyo 160, Japan. 


\section{Pacific Journal of Mathematics}

\section{Vol. 40, No. $3 \quad$ November, 1972}

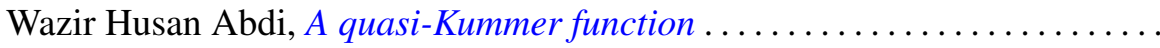

Vasily Cateforis, Minimal injective cogenerators for the class of modules of

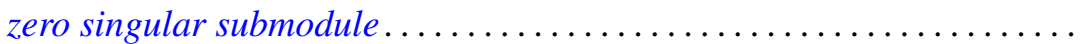

W. Wistar (William) Comfort and Anthony Wood Hager, Cardinality of

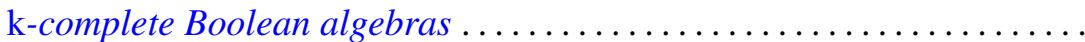

Richard Brian Darst and Gene Allen DeBoth, Norm convergence of martingales of Radon-Nikodym derivatives given a $\sigma$-lattice ..........

M. Edelstein and Anthony Charles Thompson, Some results on nearest points and support properties of convex sets in $c_{0} \ldots \ldots \ldots \ldots \ldots$

Richard Goodrick, Two bridge knots are alternating knots .

Jean-Pierre Gossez and Enrique José Lami Dozo, Some geometric properties related to the fixed point theory for nonexpansive mappings ..........

Dang Xuan Hong, Covering relations among lattice varieties .............

Carl Groos Jockusch, Jr. and Robert Irving Soare, Degrees of members of $\Pi_{1}^{0}$

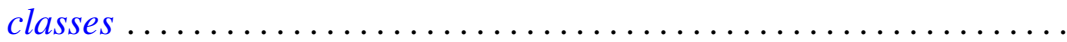

565

575

605

Leroy Milton Kelly and R. Rottenberg, Simple points in pseudoline

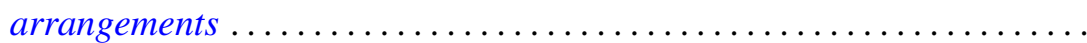

Joe Eckley Kirk, Jr., The uniformizing function for a class of Riemann surfaces....

Glenn Richard Luecke, Operators satisfying condition $\left(G_{1}\right)$ locally ... 629

T. S. Motzkin, On L $(S)$-tuples and l-pairs of matrices ... . .

Charles Estep Murley, The classification of certain classes of torsion free

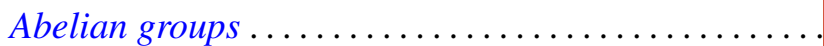

Louis D. Nel, Lattices of lower semi-continuous functions and associated topological spaces.

David Emroy Penney, II, Establishing isomorphism between tame prime

knots in $E^{3}$. . .

Daniel Rider, Functions which operate on $\mathscr{F} L_{p}(T), 1<p<2$

Thomas Stephen Shores, Injective modules over duo rings ...

Stephen Simons, A convergence theorem with boundary. .

703

Stephen Simons, Maximinimax, minimax, and antiminimax theorems and a

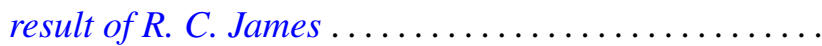

Stephen Simons, On Ptak's combinatorial lemma ........

Stuart A. Steinberg, Finitely-valued $f$-modules............

Pui-kei Wong, Integral inequalities of Wirtinger-type and fourth-order

elliptic differential inequalities .

Yen-Yi Wu, Completions of Boolean algebras with partially additive

operators ..................................

Phillip Lee Zenor, On spaces with regular $G_{\delta}$-diagonals . . . 